\title{
Towards artificial photosynthesis - Light-induced intramolecular electron transfer from manganese (II) to ruthenium (III) in a binuclear complex
}

\author{
STENBJÖRN STYRING ${ }^{a *}$, LICHENG SUN ${ }^{b}$, \\ LEIF HAMMARSTRÖMc ${ }^{\mathrm{c}}$, ROMAN DAVYDOV', \\ MATS ALMGREN' ${ }^{c}$, MIKAEL ANDERSSONc, \\ HELENA BERGLUND ${ }^{c}$, ANNA BÖRJE ${ }^{b}$, \\ PETER KORALL ${ }^{b}$, THOMAS NORRBY ${ }^{b}$, \\ CHRISTIAN PHILOUZE ${ }^{b}$ and BJÖRN ÅKERMARK ${ }^{b}$ \\ Department of Biochemistry, Center of Chemistry and Chemical Engineering, \\ University of Lund, PO Box 124, S-221 00 Lund, Sweden \\ ${ }^{b}$ Royal Institute of Technology, Department of Chemistry, Organic Chemistry, \\ S-100 44 Stockholm, Sweden \\ 'Department of Physical Chemistry, Uppsala University, PO Box 532, S-751 21 \\ Uppsala, Sweden
}

\begin{abstract}
One attractive way to harvest solar energy is to use the concepts of natural photosynthesis in an artificial system. In green plant photosynthesis, the solar energy is transformed into usable energy in the form of reduced compounds. The electrons come from water which is oxidized to molecular oxygen, thereby providing the plants with a never ending supply of reducing equivalents. In photosystem II, the photosensitizer is a chlorophyll species, P680, which is coupled to a cluster composed of four manganese ions that catalyses the water oxidation. We have tried to mimic this by the synthesis of a binuclear compound [Ru(bpy $)_{2}$ (Mebpy-Mebpy) $\left.\mathrm{MnCl}_{2}\left(\mathrm{H}_{2} \mathrm{O}\right)_{2}\right] \mathrm{Cl}_{2}$ built on bipyridine ligands containing a $\mathrm{Ru}(\mathrm{II})$ moiety (the photosensitizer) and a $\mathrm{Mn}$ (II) ion (the donor) linked via a bridging ligand. In the complex, which is structurally defined by NMR, elemental analysis and electrospray mass spectroscopy, we have observed, (1) the $\mathrm{Mn}$ is sufficiently close (about $13 \AA$ ) to interact with the $R u(I I)$ ion, and (2) intramolecular, photochemically induced electron transfer from $\mathrm{Mn}$ (II) to the photogenerated $\mathrm{Ru}(\mathrm{III})$ moiety after a light flash in the presence of an electron acceptor. We suggest that the synthesis, characterization and observation of intramolecular electron transfer in this novel Ru-Mn compound is an important step towards artificial photosynthesis.
\end{abstract}

Keywords. Artificial photosynthesis; photosystem II; polypyridene complexes; photochemical properties.

\section{Introduction}

In the energy debate, the ever flowing solar energy emerges as the most promising source for future sustainable production of fuel and electricity. One attractive way to harvest solar energy is to use the concepts of natural photosynthesis in an artificial system. One key enzyme in plant photosynthesis ${ }^{1.2}$ is photosystem II. This large protein complex (figure 1), which is located in the thylakoid membrane, contains a light-absorbing antenna unit composed of several proteins binding as many as 200

*For correspondence 

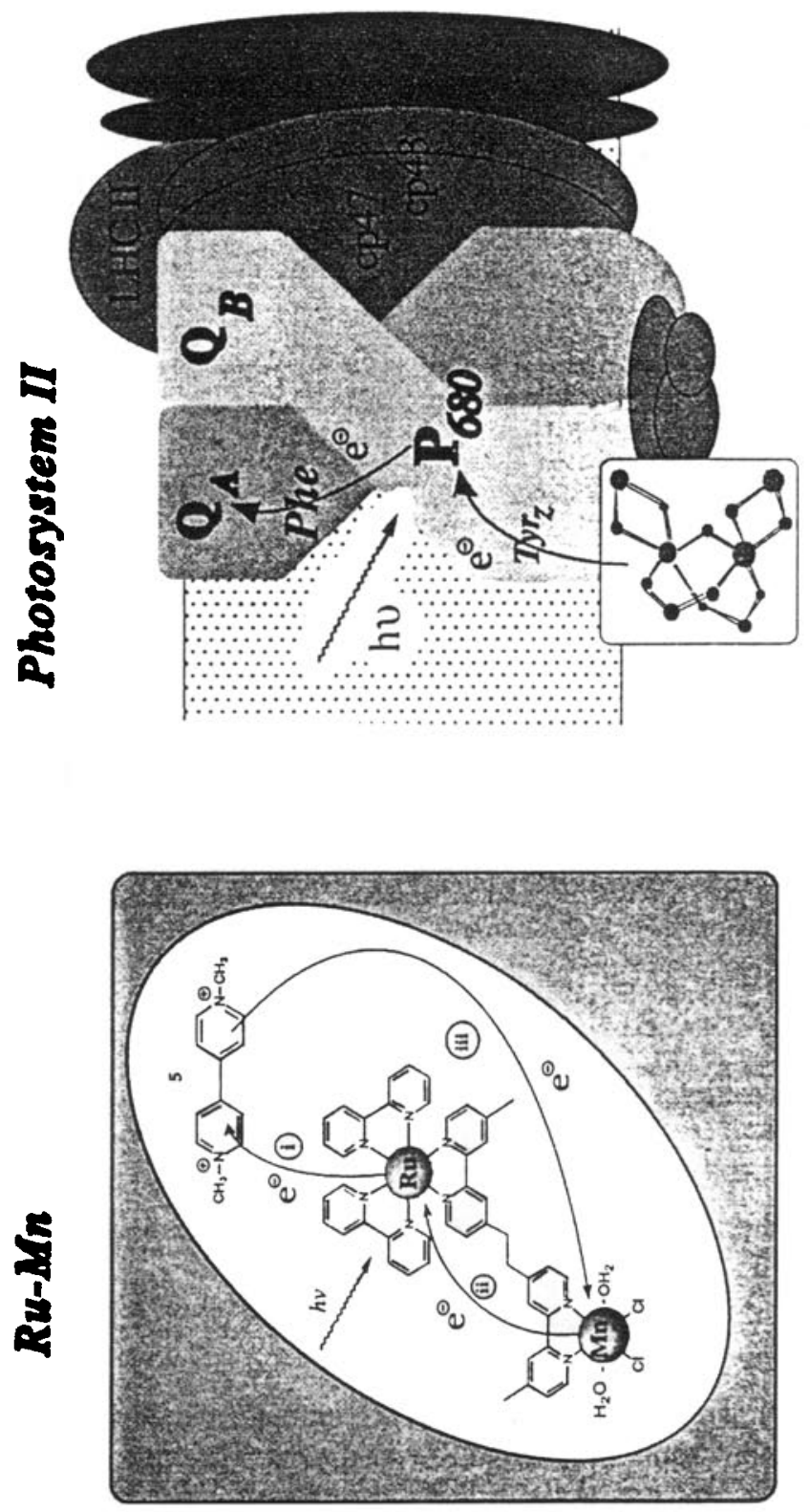

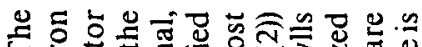

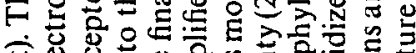

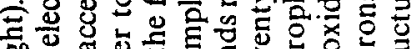
물 은

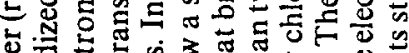

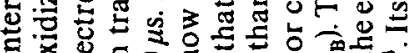

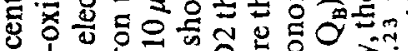

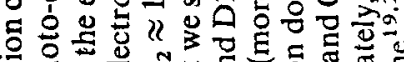

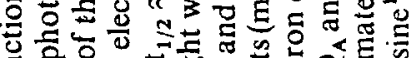
象

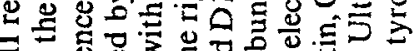

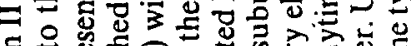
년 응 . O 영

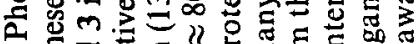

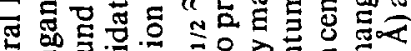

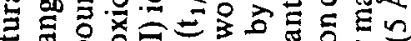

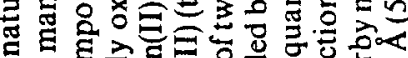

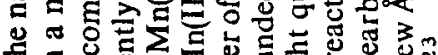

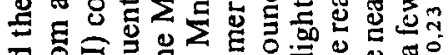

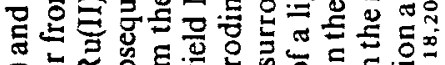

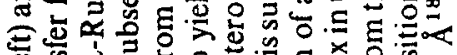

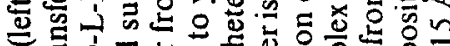

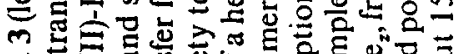
उ

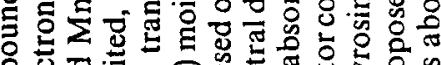
웡

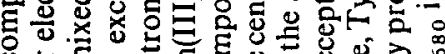
荘互. 青

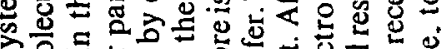

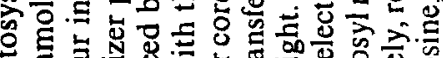
을 氜:

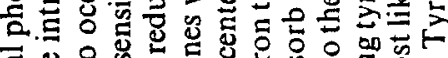

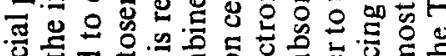
记

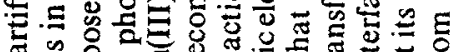

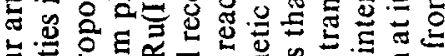

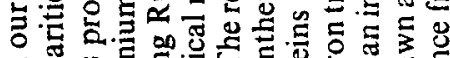

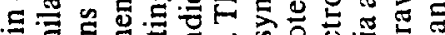

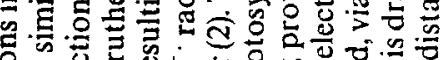
응

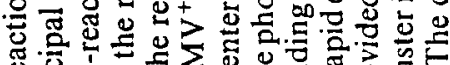

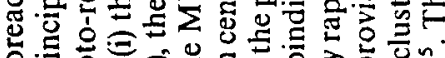

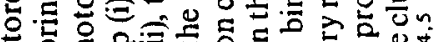

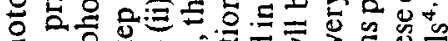

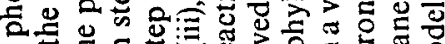

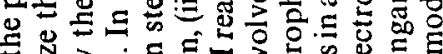

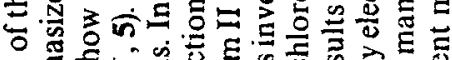

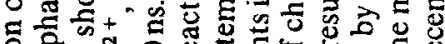
है

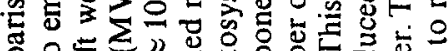

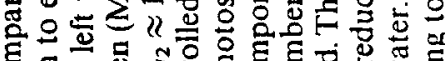

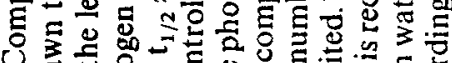

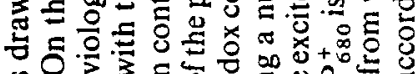

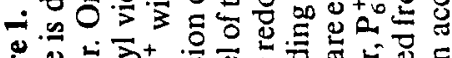

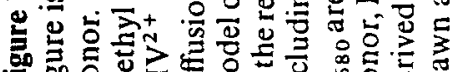

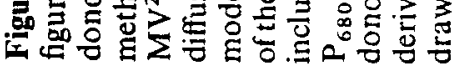


chlorophyll molecules and a reaction center part where the energy of the absorbed photons is converted into chemical energy, in a series of electron transfer events. Light energy, that is absorbed by a chlorophyll molecule in the antenna, is transferred to the reaction center, thereby triggering the conversion of solar energy into chemical energy. An important part of photosystem II is a cluster of four manganese ions ${ }^{3-5}$ which provides electrons, one for each photo event, to the photo-oxidized primary electron donor chlorophyll(s) $\mathrm{P}_{680}^{+}$. The manganese cluster (figure 1) is then able to recapture all four electrons in one step by oxidation of two water molecules to molecular oxygen. A crucial step in this process is the electron transfer from manganese to $\mathrm{P}_{680}^{+}$which occurs inside the photosystem II complex over a distance of $15-25 \AA$ and is mediated by an interfacing tyrosine sidechain (Tyrosine ${ }_{z}$, figure 1 ).

Every photosynthetic system, be it natural or artificial, must contain a photosensitizer capable of absorbing light and creating charge separation by electron transfer. Furthermore, a functional artificial photosynthetic system for energy production will also have to include a donor-system, which after oxidation is able to split water, thus supplying, endlessly, the electrons required to regenerate the photosensitizer. In the natural system, this is accomplished by the manganese cluster in photosystem II which is very efficiently coupled to the photosensitizer $P_{680}$.

In attempts to mimic crucial reactions in the natural photosynthesis, much effort has been spent studying photochemical energy conversion ${ }^{6,7}$ in, for example, covalently linked molecular donor-acceptor systems ${ }^{8-10}$. However, few efforts have been made to mimic the structure and function of the electron donor side in photosystem II containing the manganese cluster. We have now been able to mimic some essential features of this step by preparing a binuclear ruthenium-manganese complex, in which the ruthenium upon illumination donates an electron to an external acceptor, then recaptures it from bound manganese via intramolecular electron transfer (figure 1).

\section{Results and discussion}

Polypyridine complexes of ruthenium(II) play an important role as photo electron donors in many model systems. On illumination, these complexes transfer electrons to internal or external acceptors ${ }^{1-13}$. Numerous such systems have been studied, where the ruthenium compounds have been bound to electron donors and acceptors in order to achieve efficient charge separation ${ }^{8}$. Also, some cyclic systems have been developed, generally using a sacrificial donor such as an amine, to reduce the photo-generated $\mathrm{Ru}(\mathrm{III})$ ion ${ }^{7}$. In photosystem II, this is accomplished by intramolecular electron transfer from the manganese cluster to the oxidized chlorophyll donor $\mathrm{P}_{680}^{+}{ }^{14,15}$ (figure 1). We therefore decided to study if bimetallic ruthenium(II)-manganese(II) complexes could be prepared, in which $\mathrm{Ru}(\mathrm{II})$ could function as the photo-active chromophore and the $\mathrm{Mn}$ (II) ion as the coordinatively bound donor, providing electrons to the $\mathrm{Ru}(\mathrm{III})$ ion, which is formed upon illumination.

In the synthesis, we started with the bridging ligand $(\mathrm{L}) \mathbf{1}^{16}$, which we first reacted with bis(bpy)ruthenium(II) chloride ${ }^{17}$ in refluxing methanol. This resulted in compound 2 which gave the dinuclear $\mathrm{Mn}$ (II)-L-Ru(II) complex 3 upon treatment with manganese(II) chloride (figures 1, 2). The structures of 2 and 3 were supported by elemental analysis, high resolution electrospray mass spectroscopy and NMR spectroscopy $(500 \mathrm{MHz})$. In complex 3 , the distance between the $\mathrm{Mn}(\mathrm{II})$ and $\mathrm{Ru}(\mathrm{II})$ moieties was estimated to approximately $13 \AA$ for the most extended conformation by molecular 

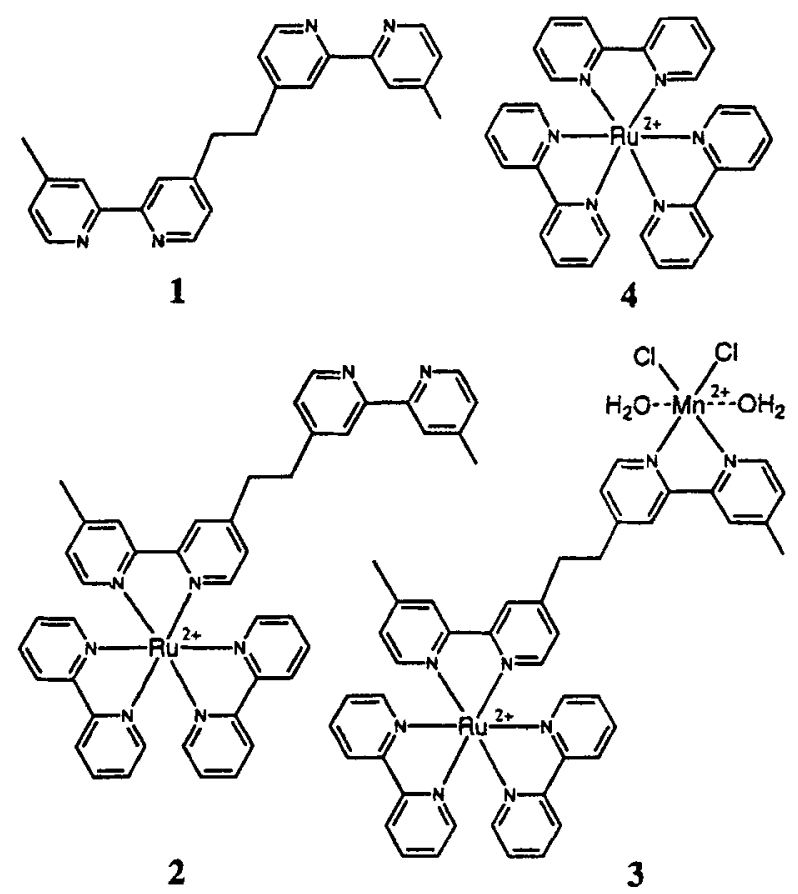

Figure 2. Structures of the ligand 1, 1,2-bis [4-(4'-methyl-2,2'-bipyridyl)] ethane (Mebpy-Mebpy) and the complexes 2: [Ru(bpy) ${ }_{2}(\mathrm{Mebpy}-\mathrm{Mebpy}) \mathrm{Cl}_{2}, 3:\left[\mathrm{Ru}(\mathrm{bpy})_{2}\right.$ (Mebpy-Mebpy) $\left.\mathrm{MnCl}_{2}\left(\mathrm{H}_{2} \mathrm{O}\right)_{2}\right] \mathrm{Cl}_{2}$ 4: $\left[\mathrm{Ru}(\mathrm{bpy})_{3}\right] \mathrm{Cl}_{2}$. Rapid electron transfer was observed in the bimetallic system $\mathrm{Mn}$ (II)-L-Ru(II), complex 3.

Towards artificial photosynthesis. Electron transfer from bound manganese(II) to photogenerated ruthenium(III)." Stenbjörn Styring ${ }^{a *}$ and Björn Åkermark ${ }^{b *}$.

mechanics calculations. This should be close enough for efficient electron transfer. In photosystem II the corresponding distances between the redox components (the $\mathrm{Mn}$ cluster, Tyrosine $e_{z}$ and $P_{680}$, figure 1 ) involved in the electron transfer to $P_{680}$ is $10-15 \AA^{18-20,23}$.

We investigated whether the $\mathrm{Mn}$ part in complex 3 affects the photochemical properties of the Ru(II) part of the complex. Comparison of the steady state fluorescence spectra of 3 and the related compounds 2 and 4 (figure 2) showed that the wavelength of the emission maximum was essentially the same in all three. In contrast, the emission was considerably quenched in 3 compared to 2 and 4 (not shown). Furthermore, and very importantly, kinetic fiuorescence measurements revealed (not shown) that the rate constant for the excited state quenching was independent of the concentration of 3 . This shows that the quenching was the result of interaction within the supermolecule 3 . The manganese is thus, most probably, suitably positioned to interact with the excited ruthenium, but it does not quench the fluorescence completely.

The question then arises if intramolecular electron transfer from $\mathrm{Mn}$ (II) to photogenerated $\mathrm{Ru}(\mathrm{III})$ is possible within complex 3 , much in the same way as is observed for the manganese cluster in photosystem II (figure 1$)^{1,2,14,15}$. This was investigated by flash photolysis experiments in the presence of the external electron acceptor, methyl viologen $\left(\mathrm{MV}^{2+}, 5\right.$ in figure 1), comparing complexes 2,3 and 4 (figure 3). Following 


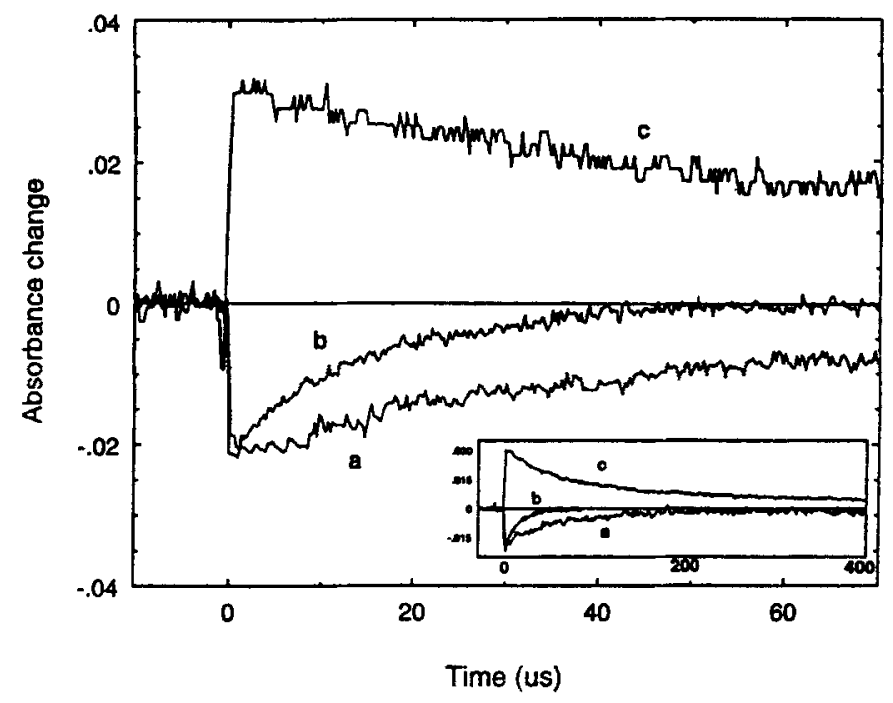

Figure 3. Transient absorption curves showing the recovery of $\mathrm{Ru}(\mathrm{II})$ and decay of the methyl viologen radical $\left(\mathrm{MV}^{+} \cdot\right.$ ) measured by absorption at $458 \mathrm{~nm}$ and $600 \mathrm{~nm}$ respectively after a $15 \mathrm{~ns}$ laser fiash $\left(i_{\mathrm{ex}}=465 \mathrm{~nm}\right)$ that produced $\mathrm{Ru}(\mathrm{III})$ and the methyl viologen radical $\left(\mathrm{MV}^{+}\right.$) by photoinduced electron transfer (compare figure 1). The lower half of the graph shows the rapid formation of $R u(I I I)$ as a step-wise decrease in absorption (on the time-scale presented). The Ru(II) absorption recovery is monitored for 2 , trace (a), and 3 , trace (b). For 3 the recovery is very rapid and follows first order kinetics $\left(\mathrm{t}_{1 / 2} \approx 10 \mu \mathrm{s}\right)$. For 2 the recovery is slower, yet diffusion controlled, and follows second order kinetics with a rate constant of $\approx 5 \times 10^{9} \mathrm{M}^{-1} \mathrm{~s}^{-1}$. The upper half (trace c) shows the decay of the $\mathrm{MV}^{+}$, generated after the laser flash, to $\mathrm{MV}^{2+}$ as measured by the decrease in absorption at $600 \mathrm{~nm}$. The rate of the decay is the same in the reactions with $\mathbf{2}$ and 3 and follows second order kinetics with the rate constant $5 \times 10^{9} \mathrm{M}^{-1} \mathrm{~s}^{-1}$. The insert in the figure shows the same decay curves (a)-(c) at a longer time scale. Deoxygenated acetonitrile solutions of initial concentrations $70 \mu \mathrm{M}$ of $\mathrm{Ru}(\mathrm{II})$ and $10 \mathrm{mM}$ of $\mathrm{MV}^{2+}$ were used. The flash produced about $2 \mu \mathrm{M}$ each of $\mathrm{Ru}(\mathrm{III})$ and $\mathrm{MV}^{+}$.

a laser flash, the oxidation of $\mathrm{Ru}(\mathrm{II})$ to $\mathrm{Ru}(\mathrm{III})$ and its subsequent recovery was monitored. In compound 2 , the excited state of ruthenium was rapidly quenched by electron transfer to $\mathrm{MV}^{2+}$, generating $\mathrm{Ru}(\mathrm{III})$ and the methyl viologen radical $\left(\mathrm{MV}^{+}\right.$) (figure 3, traces a and c; see also ref. 21). The recovery of $\mathrm{Ru}(\mathrm{II})$ and the decay of the $\mathrm{MV}^{+}$. radicals in this complex followed similar second order kinetics with rate constants of about $5 \times 10^{9} \mathrm{M}^{-1} \mathrm{~s}^{-1}$ (traces a and $\mathrm{c}$ in figure 3). This shows that the products of the charge separation recombine on the time scale of a few hundred $\mu \mathrm{s}$ (first half-life $\mathrm{t}_{1 / 2} \approx 80 \mu \mathrm{s}$ at the concentration levels obtained in the experiments). The behavior of complex 4 was similar (not shown).

In the bimetallic $\mathrm{Mn}(\mathrm{II})-\mathrm{L}-\mathrm{Ru}(\mathrm{II})$ complex 3 , on the other hand, the situation was very different. After the flash, the $\mathrm{MV}^{+}$. radical was generated to the same extent as in the experiment with 2 . The $\mathrm{MV}^{+}$. radical also decayed at about the same rate as in the experiments with 2 and $\mathbf{4}$, suggesting that it recombined with an oxidized species in 3 at about the same rate as it does with $\mathrm{Ru}$ (III) in 2 and 4 . However, in sharp contrast, the reduction of $R u(I I I)$ to $R u(I I)$ was found to be much faster in 2 and $4\left(t_{1 / 2} \approx 10 \mu \mathrm{s}\right.$ for trace $b$, figure 3 ). This means that the oxidized $\mathrm{Ru}(\mathrm{III})$ moiety in the bimetallic complex 
3 must have received an electron from a source not being $\mathrm{MV}^{+}$, and which is not present in 2 and 4. Analysis of the absorbance recovery traces for complex 3 (figure 3, trace b) revealed a single exponential process with $\mathrm{k} \approx 5 \times 10^{4} \mathrm{~s}^{-1}$ that was concentration independent over the range examined ([complex 3] $\left.=2-10 \times 10^{-5} \mathrm{M}\right)$. We propose that this process reflects intra molecular electron transfer from the $\mathrm{Mn}$ (II) moiety to the oxidized $\mathrm{Ru}(\mathrm{III})$, thus regenerating $\mathrm{Ru}(\mathrm{II})$. At higher concentrations of complex 3 , the $\mathrm{Ru}(\mathrm{III})$ ion was reduced (in addition to the first order reaction) also in a second order process of, as yet, unknown origin. It should also be mentioned that the Mn(III) species formed in the flash experiments is expected to recombine with the $\mathrm{MV}^{+\cdot}$ radicals with more or less the same diffusion controlled rate constant as for the $\mathrm{Ru}(\mathrm{III})-\mathrm{MV}^{+}$. recombination. This might explain why the $\mathrm{MV}^{+}$. decay curves were identical in the experiments with both complex 2 and complex 3 (figure 3 ).

Support for our interpretation was also obtained by a combined EPR spectroscopy and stopped-flow study of the reaction between the dinuclear complex 3 and tris(bpy)Ru(III) hexafluorophosphate. The $\mathrm{Mn}(\mathrm{II})$ ion in complex 3 and $\mathrm{Ru}(\mathrm{III})$ in tris(bpy)Ru(III) give rise to easily observable, characteristic EPR spectra (figure 4). In contrast, $\mathrm{Ru}(\mathrm{II})$ and $\mathrm{Mn}(\mathrm{III})$ are EPR-silent ${ }^{22}$. When complex 3 was mixed with an equimolar amount of tris(bpy)Ru(III), the signais from $\mathrm{Ru}(\mathrm{III})$ and $\mathrm{Mn}$ (II) quickly disappeared (figure 4A, B). This directly shows, that the potential of $\mathrm{Ru}(\mathrm{III})$ is high enough to allow oxidation of the $\mathrm{Mn}$ (II) part in complex 3, i.e. this process is thermodynamically favourable. Using visible light spectroscopy it could be shown that the tris(bpy)Ru(II) was formed in the reaction, having the characteristic absorption and

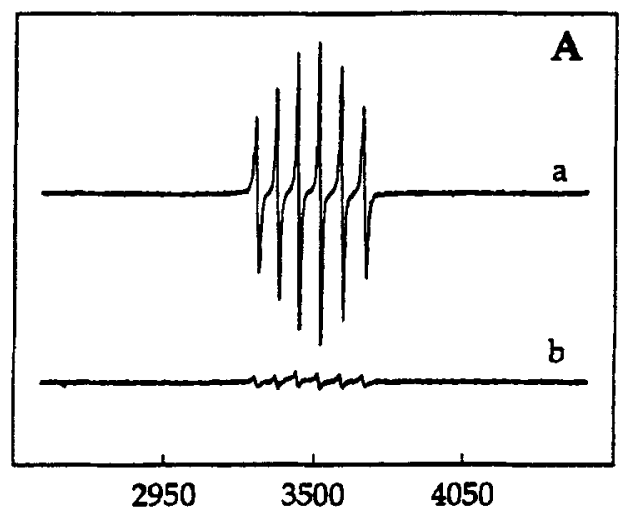

Field (mT)

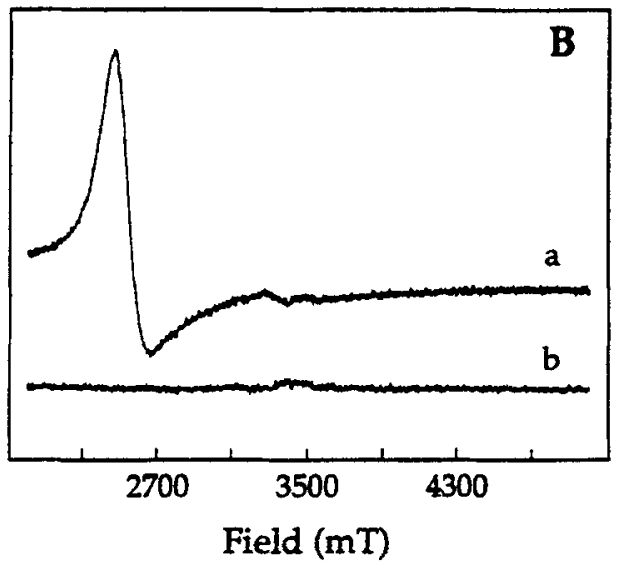

B (1)

Figure 4. X-band EPR spectra showing the oxidation of the $\mathrm{Mn}$ (II) moiety in 3(A) and the simultaneous reduction of tris (bpy) Ru(III) (B). The EPR spectrum of 3 shows the typical 6-line EPR spectrum from Mn(II) (spectrum a in panel A) while the EPR spectrum of tris (bpy) $R u(I I I)$ shows a spectrum typical of $R u(I I I)$ (spectrum a in panel B). When the two compounds were mixed in equimolar concentrations the spectrum from $\mathrm{Mn}$ (II) and $\mathrm{Ru}$ (III) disappeared on the same timescale (to produce spectra $b$ in panels $A$ and $B$ ). The EPR spectra were recorded with a Bruker ESP380 spectrometer equipped with an Oxford instruments temperature controller. The conditions for the EPR spectra were in A and B respectively, $\mathrm{T} 293 \mathrm{~K}$ and $77 \mathrm{~K}$; modulation amplitude $0.5 \mathrm{mT}$ and $1.0 \mathrm{mT}$; microwave frequency $9.778 \mathrm{GHz}$ and $9.50 \mathrm{GHz}$; microwave power $9.8 \mathrm{~mW}$.

Towards artificial photosynthesis. Electron transfer from bound manganese(II) to photogenerated ruthenium(III)." Stenbjöm Styring ${ }^{2 *}$ and Björn Åkermark ${ }^{b *}$. 
emission properties (not shown). The kinetics for the intermolecular electron transfer was measured under stopped-fiow conditions, and the bimolecular rate constant was found to be about $1 \times 10^{7} \mathrm{M}^{-1} \mathrm{~s}^{-1}$. In the transient absorption measurements on complex 3 (figure 3 ) at a manganese concentration corresponding to $\approx 70 \mu \mathrm{M}$, this rate constant would correspond to a first half life $t_{1 / 2} \approx 1.0 \mathrm{~ms}$ for the recovery of $\mathrm{Ru}$ (II). This is approximately two orders of magnitude longer than the experimentally observed half life $\left(\mathrm{t}_{1 / 2} \approx 10 \mu \mathrm{s}\right)$. It is also much longer than the anticipated half life for recovery of $\mathrm{Ru}(\mathrm{II})$ by reaction with $\mathrm{MV}^{+} \cdot\left(\mathrm{t}_{1 / 2} \approx 80 \mu \mathrm{s}\right.$, figure 3$)$. Therefore, these results strongly support our proposal that $R u(I I I)$, formed upon irradiation of compound 3, is rapidly reduced by electron transfer from bound $\mathrm{Mn}(\mathrm{II})$.

\section{Conclusions}

The photoinduced events we propose in figure 1 emerge as a reasonable artificial model for the individual electron transfer steps from manganese to $\mathrm{P}_{680}^{+}$, the photo-oxidized electron-donor in photosystem II. The experimental establishment of a photo-induced rapid redox reaction between a photo-generated $\mathrm{Ru}(\mathrm{III})$ and a coordinatively bound $\mathrm{Min}(\mathrm{II})$ is, to the best of our knowledge, the first example of a specific photoinduced redox interaction between these species. We are presently investigating bridging ligands of different geometry and size, varying the distance and nature of the connecting bridge between the ruthenium and manganese centra on the process. Hopefully, we will thereby be able to optimize these supramolecular complexes for fast and efficient electron transfer. However, in the natural photosystem II the catalytic entity, catalyzing the oxidation of water, is a cluster of four high-valent manganese ions, $\mathrm{Mn}$ (III) or $\mathrm{Mn}(\mathrm{IV})$, held together by oxygen bridges $^{3-5}$. We are therefore in the process of synthetizing more complex models containing two or four manganese ions coordinatively linked to one or several ruthenium centra, which are potentially able to work as multi-electron donors and perform the desired photooxidation of water to oxygen.

\section{Acknowledgements}

The high-resolution mass spectroscopy experiments were conducted in collaboration with Drs $G$ Stenhagen and J Mårtensson, Chalmers University of Technology, Göteborg, Sweden. The work was supported from the Swedish Natural Science Research Council and the Knut and Alice Wallenberg Foundation. This is publication no 5 from the Consortium for Studies of Artificial Photosynthesis, Sweden.

\section{References}

1. Barber J and Andersson B 1994 Nature 370 31-34

2 Andersson B A and Styring S 1991 in Current Topics in Bioenergetics (ed.) C P Lee, vol. 16, 1-81 Academic Press, San Diego

3. George G N, Prince R C, and Cramer S P 1989 Science 243 789-791

4. Yachandra V K, DeRose V J, Latimer M J, Mukerji I, Sauer K, and Klein M P 1993 Science $260675-678$

5. Dau H, Andrews J C, Roelofs T A, Latimer M, Liang W, Yachandra V K, Sauer K and Klein M P 1995 Biochemistry 34 5274-5287

6. Lampert C M 1995 Sol. Energy Mater. Sol. Cells 38 1-590

7. Willner I and Willner B 1991 Top. Curr. Chem. 159 153-218 
8. Balzani V and Scandola F 1991 Supramolecular Photochemistry (Ellis Horwood, Chichester)

9. Kurrek H and Huber M 1995 Angew. Chem. Int. Ed. Engl. 43 849-866

10. Gust D and Moore T A 1991 Top. Curr. Chem. 159 103-152

11. Meyer T J 1989 Acc. Chem. Res. 22 163-170

12. Juris A, Balzani V, Barigelletti F, Campagna S, Belser P and von Zelewsky A 1988 Coord. Chem. Rev. 84 85-277

13. Balzani V, Juris A, Venturi M, Campagna S and Serroni S 1996 Chem. Rev. 96 759-833

14. Seibert M 1993 In The Photosynthetic Reaction Center (eds) J Deisenhofer and J R Norris vol. I, 319-356 (Academic Press, San Diego)

15. Diner B A and Babcock G T 1996 in Oxygenic Photosynthesis: The Light Reaction (eds) D Ort and Yocum C (Kluwer, Dordrecht, in press.)

16. Elliott C M, Freitag R A and Blaney D D 1985 J. Am. Chem. Soc. 107 4647-4655

17. Sullivan B P, Salmon D J and Meyer T J 1978 Inorg. Chem. 17 3334-3341

18. Kodera Y, Hara H, Astashkin A V, Kawamori A and Ono T 1995 Biochim. Biophys. Acta 1232 43-51

19. Gilchrist Jr M L, Ball J A, Randall D W and Britt R D 1995 Proc. Natl. Acad. Sci. USA 92 9545-9549

20. Hoganson C W and Babcock G T 1988 Biochemistry 27 5848-5855

21. Kalyanasundaram K 1992 Photochemistry of Polypyridine and Porphyrin Complexes, (Academic, London)

22. Abragam A and Bleaney B 1986 Electron Paramagnetic Resonance of Transition Ions(Dover, New York)

23. Svensson B, Etchebest C, Tuffery P, van Kan P, Smith J and Styring S 1996 Biochemistry, in press 